\title{
PURCHASE BEHAVIOR RELATED TO RECYCLED PRODUCT IN CHINA
}

Wong Ming Wong, Shantou University, wmwong@stu.edu.cn Hao Fan Mo, Jinwen University of Science and Technology, Mo1111@just.edu.tw

dx.doi.org/10.18374/RBR-13-2.15

\begin{abstract}
The purpose of this study is to explore the purchase intention and behavior of consumers to purchase a recycled product via a correlative research approach. The study explores the correlation between reference group, age, gender, income, purchase intention, and purchase behavior of consumers in terms of the Theory of Reasoned Action model. The research sample has 451 persons via a simple random sampling method over a four-week period collection in Shanghai, China. The results indicate the income and reference group of consumers have a significant influence on consumers' purchase intention, which turns into purchase behavior in China.
\end{abstract}

Keywords: recycled product, purchase intention, purchase behavior, China 